\title{
ANALISIS KARAKTERISTIK DAN KEBUTUHAN RUANG PARKIR KENDARAAN DI AREA PASAR PAMARAYAN
}

\author{
Sukri $^{1}$, Telly Rosdiyani ${ }^{2}$, dan Euis Amilia ${ }^{3}$ \\ 1,2,3 Program Studi Teknik Sipil, Universitas Banten Jaya, Jl. Ciwaru II No. 73 Kota Serang, Banten \\ Email: Ukijangkis15@gmail.com \\ Email: Tellyrosdiyani004@gmail.com \\ Email: Euisamilia@yahoo.com
}

\begin{abstract}
ABSTRAK
Masalah kebutuhan fasilitas parkir sering terjadi intentik dengan bertambahnya tingkat kepemilikan kendaraan. Hal tersebut menyebabkan kebutuhan akan ruang parkir menjadi sangat penting. Secara Visual tingginya jumlah pengunjung Pasar Pamarayan dapat di lihat banyaknya kendaraan yang memarkirkan kendaraannya di dalam pasar maupun disekitar pasar. Penelitian ini bertujuan untuk dapat menganalisi kapasitas dan kebutuhan ruang parkir, adapun metode yang digunakan deskripsi kuantitatif yang membutuhkan data primer dan data skunder, Data primer diperoleh dengan mengamati pergerakan jumlah kendaraan parkir selama dua hari yang dimulai pukul 6 sampai jam 12 siang, serta wawancara pihak terkait, sedangkan data skunder didapatkan luas parkir Pasar Pamarayan. Hasil penelitian ini dapat mengetahui karakteristik parkir dimana nilai akumulasi tertinggi pada hari sabtu di lokasi A , durasi rata-rata terkecil pada lokasi A, sedangkan terbesar pada lokasi B dan kebutuhan ruang parkir lokasi A seluas $252 \mathrm{~m}^{2}$ sedangkan luas area exsisting sebesar $185 \mathrm{~m}^{2}$ lokasi B membutuhkan ruang parker 126 $\mathrm{m}^{2}$ luas exsisting $72 \mathrm{~m}^{2}$ satuan ruang parkir. Dapat disimpulkan bahwa lahan parker Pasar Pamarayan sudah tidak mampu menampung jumlah kendaraan yang akan parkir pada lokasi parkir A dan B bermasalah, baik di hari sabtu maupun hari minggu, dikarenakan akumulasi tertinggi parkir melebihi kapasitas normal. Nilai IP $>100 \%$. Adapun penerapan kebijakan parkir bisa dilakukan dengan manajemen pengaturan parkir maupun penambahan ruang parkir adalah solusi yang baik untuk mengatasinya, pihak pengelola perlu mempertimbangkan untuk menyediakan lokasi parkir yang lebih besar agar dapat mengimbangi jumlah kendaraan yang makin meningkat.
\end{abstract}

Katakunci: Karakteristik, Ruang Parkir, PasarPamarayan

\begin{abstract}
ABSTRAC
The problem of the need for parking facilities is often intent on increasing the level of vehicle ownership. This makes the need for parking spaces very important. Visually, the high number of visitors pamarayan market can be seen the number of vehicles that park their vehicles in the market and around the market. This research aims to be able to analyze the capacity and needs of parking spaces, as for the method used quantitative descriptions that require primary data and secondary data, primary data obtained by observing the movement of the number of parking vehicles for two days starting at 6 to $12 \mathrm{pm}$, as well as interviews related parties, while the data skunder obtained extensive parking Pamarayan Market. The results of this study can find out the characteristics of parking where the highest accumulated value on Saturday in location A, the smallest average duration at location $A$, while the largest at location $B$ and the need for parking space location $A$ area of $252 \mathrm{~m} 2$ while the exsisting area is $185 \mathrm{~m} 2$, location $B$ requires a parker room of $126 \mathrm{~m} 2$ exsisting area of $72 \mathrm{~m} 2$ units of parking space. It can be
\end{abstract}


concluded that the parker area of Pamarayan Market has been unable to accommodate the number of vehicles that will park at the problematic $A$ and B parking locations, both on Saturdays and Sundays, due to the highest accumulation of parking exceeding normal capacity. Ip value assesses 100\%. While the implementation of parking policies can be done with the management of parking arrangements and the addition of parking spaces is a good solution to overcome them, the management needs to consider providing a larger parking location in order to compensate for the increasing number of vehicles. Keyword: Karakteristik, Ruang Parkir, PasarPamarayan

\section{PENDAHULUAN}

Pasar merupakan pembangkit (stimulator) pertumbuhan suatu kawasan atau wilayah. Hal ini terjadi karena fungsi ganda pasar sebagai pengumpul barang dan jasa sekaligus sebagai pusat distribusinya (Royadji Darma dkk. 2019). Kegiatan-kegiatan tersebut akan menyebabkan pemusatan aktifitas sehingga menimbulkan tarikan perjalanan menuju pasar terebut. Hal itu akan menyebabkan banyaknya volume kendaraan yang keluar masuk, sehingga diperlukan suatu tempat untuk menampung kendaraan selama pengguna kendaraan tersebut melakukan aktifitasnya.

Pasar umum Pamarayan berlokasi di Kampung Pamarayan, Desa Pamarayan, Kecamatan Pamarayan, Kabupaten Serang. Barang-barang yang dijual di Pasar Pamarayan sangatlah beragam mulai dari kebutuhan sehari-hari seperti bahan pangan, pakaian, elektronik, hingga toko emas. Transaksi jual beli tersebut dapat meningkatkan taraf perekonomian di daerah Pamarayan, dalam peningkatan hal itu tentunya harus didukung dengan fasilitas yang memadai, salah satunya adalah penataan dan penyediaan parkir di pasar tersebut, pengunjung maupun pedagang dapat lancar dalam akifitasnya maupun memberikan keamanan penyimpanan kendaraannya.

Masalah kebutuhan fasilitas parkir adalah hal yang biasa terjadi seiring terus bertambahnya tingkat kepemilikan kendaraan (Rosdiyani, T. 2016) Hal tersebut menyebabkan kebutuhan akan fasilitas parkir menjadi sangat penting. Tingginya jumlah pengunjung Pasar Pamarayan denga melihat dari banyaknya kendaraan yang memarkirkan kendaraannya di dalam pasar maupun disekitar pasar. Berdasarkan latar belakang itu penelitian ini bertujuan untuk mengetahui kapasitas dan kebutuhan parkir dan selain itu pula mengetahi karakteristik parkir serta menganalisa pemasalahan yang terjadi di pasar Pamarayan.

\section{METODOLOGI PENELITIAN}

\section{Pengumpulan Data}

Dalam Penelitian ini memerlukan data yang merupakan langkah penting dalam melakukan dan menyelesaikan penelitian. Dalam pengumpulan data ini, data yang dibutuhkan yaitu data primer. Data primer diperoleh dari hasil pengamatan oleh surveyor di lapangan. Data primer dalam penelitian ini berupa jumlah kendaraan yang parkir di pasar Pamarayan serta wawancara dengan pihak terkait sedangkan data skunder didapatkan luas area pasar Pamarayan. Lokasi penelitian ini berada di Pasar Pamarayan. Pengambilan data dilakukan selama 2 hari yaitu pada hari Sabtu dan Minggu yang mana pada masing-masing dimulai pukul 06.00-12.00 WIB. Alasan mengapa mengambil penelitian dihari sabtu dan minggu, hal itu karenan pada hari sabtu dan minggu merupakan puncak ketinggian kedatangan pengunjung pasar. Proses pengumpulan data dilapangan dilakukan dengan metode survai, survai ini meliputi pencataan nomor kendaraan masuk dan keluar setiap lokasi parkir pasar pamarayan. Data yang didapat kemudian dilakukan pengolahan data dengan menggunakan bantuan Microsoft Excel. Proses survai ini dibantu oleh 5 orang surveyor yang disebar ke 2 lokasi parkir berbeda yaitu lokasi A dan B

\section{Metode Analisis}

Berdasarkan pengumpulan data yang didapatkan dari data jumlah kendaraan dapat dianalisis parameter nilai-nilai Frekuensi Parkir, Akumulasi Parkir, Durasi Parkir ,Tingkat Pergantian Parkir, Indeks Parkir,Kapasitas dan Kebutuhan Parkir yang menunjukan karakteristik parkir dan kebutuhan ruang lainnya.( Dayana, E.2012).Adapun untuk mengetahui solusi kebijakan penulis menggunakan parameter dari presepsi responden. 


\section{DATA DAN ANALISA}

\section{Karakterisrik Parkir}

Data rekapitulasi survai kendaraan pada tiap lokasi parkir bisa dilihat pada Tabel 1 dibawah ini :

Tabel 1. Rekapitulasi Data Kendaraan Keluar Masuk Tiap Lokasi Parkir

\begin{tabular}{|c|c|c|c|c|}
\hline \multirow{3}{*}{ Lokasi Parkir } & \multicolumn{4}{|c|}{ Jumlah Kendaraan Tiap Lokasi } \\
\hline & \multicolumn{4}{|c|}{ Sabtu } \\
\hline & $\begin{array}{c}\text { Sebelum } \\
\text { Jam } 06.00\end{array}$ & $\begin{array}{c}\text { Setelah } \\
\text { Jam } 12.00\end{array}$ & $\begin{array}{c}\text { Kendaraan } \\
\text { Masuk }\end{array}$ & $\begin{array}{c}\text { Kendaraan } \\
\text { Keluar }\end{array}$ \\
\hline $\mathrm{A}$ & 25 & 25 & 143 & 143 \\
\hline \multirow[t]{3}{*}{$\mathrm{B}$} & 10 & 21 & 74 & 63 \\
\hline & \multicolumn{4}{|c|}{ Minggu } \\
\hline & $\begin{array}{c}\text { Sebelum } \\
\text { Jam } 06.00\end{array}$ & $\begin{array}{c}\text { Setelah } \\
\text { Jam } 12.00\end{array}$ & $\begin{array}{c}\text { Kendaraan } \\
\text { Masuk }\end{array}$ & $\begin{array}{c}\text { Kendaraan } \\
\text { Keluar }\end{array}$ \\
\hline $\mathrm{A}$ & 8 & 22 & 117 & 103 \\
\hline $\mathrm{B}$ & 17 & 24 & 61 & 54 \\
\hline
\end{tabular}

Berdasarkan Tabel 1 menunjukan bahwa pada lokasi A lebih banyak dari pada lokasi B pada hari sabtu namun sebaliknya lokasi A lebih sedikit dari pada lokasi B pada hari minggu hal ini menunjukan bahwa di hari sabtu pengunjung membeli kebutuhannya dalam mempersiapkan untuk hari minggunya.

\section{Frekuensi Parkir}

Perhitungan Frekuensi Parkir diperlukan untuk mengetahui jumlah kendaraan yang parkir pada lahan yang tersedia saat penelitian berlangsung hingga selesai. Untuk menghitung frekuensi parkir digunakan sebagai berikut (Departemen Perhubungan Direktur Jenderal Perhubungan Darat.1998).

Frekuensi $=\mathrm{Nin}+\mathrm{X}$

Dimana :

$$
\begin{array}{ll}
\text { Nin } & \text { : Jumlah kendaran yang masuk } \\
\mathrm{X} & \text { : Kendaraan yang sudah ada sebelum survai }
\end{array}
$$

Berdasarkan rumus diatas dan dilakukan pengamatan dilapangan, maka diperoleh data seperti pada Tabel dibawah ini :

\begin{tabular}{|c|c|c|c|}
\hline \multirow{3}{*}{$\begin{array}{l}\text { Lokasi } \\
\text { Parkir }\end{array}$} & \multicolumn{3}{|c|}{ Jumlah Kedaraan Tiap Lokasi } \\
\hline & \multicolumn{3}{|c|}{ Sabtu } \\
\hline & $\begin{array}{c}\text { Kendaraan } \\
\text { Masuk Hari } \\
\text { Sabtu } \\
\end{array}$ & Kendaraan Yang Sudah Ada & Total \\
\hline A & 143 & 25 & 168 \\
\hline $\mathrm{B}$ & 74 & 10 & 84 \\
\hline \multirow[b]{2}{*}{$\begin{array}{l}\text { Lokasi } \\
\text { Parkir }\end{array}$} & \multicolumn{3}{|c|}{ Minggu } \\
\hline & $\begin{array}{c}\text { Kendaraan } \\
\text { Masuk Hari } \\
\text { Minggu } \\
\end{array}$ & Kendaraan Yang Sudah Ada & Total \\
\hline A & 117 & 8 & 125 \\
\hline $\mathrm{B}$ & 61 & 17 & 78 \\
\hline
\end{tabular}

Tabel 2. Rekapitulasi Frekuensi Parkir Hari Sabtu Dan Minggu 
Berdasarkan Tabel 2 menunjukan bahwa pada hari minggu terjadi penurunan angka kendarann yang masuk area parkir pasar dibanding pada hari sabtu. Dimana pada hari sabtu ada sebanyak 168 kendaraan pada lokasi parkir A dan 84 kendaraan pada lokasi parkir B, sedangkan pada hari minggu hanya ada 125 kendaraan pada lokasi parkir A dan 78 kendaran pada lokasi parkir B. Dikarenakan hari sabtu merupakan hari pasar bagi Pasar Pamarayan dan jumlah pedagang lebih banyak dari hari biasanya, tentu barang yang dijual lebih banyak dan bervariasi. Hal inilah yang mengakibatkan jumlah pengunjung pasar lebih banyak dari hari selain hari pasar

\section{Akumulasi Parkir}

Akumulasi parkir diperlukan untuk mengetahui banyaknya kendaraan yang masuk area parkir pasar pada selang waktu tertentu. (Departemen Perhubungan Direktur Jenderal Perhubungan Darat.1998). Data ini diperoleh dengan cara menghitung kendaraan yang masuk area parkir ditambah kendaraan yang sudah ada sebelum waktu penelitian kemudian dikurangi kendaraan yang keluar, Maka akan diperoleh jumlah maksimum kendaraan yang terparkir pada waktu tertentu. Contoh perhitungan akumulasi parkir pada lokasi parkir A hari sabtu sebagai berikut :

Akumulasi parkir = Qin - Qout + Qs

Contoh dari Table 3 dibawah Jumlah kendaraan yang masuk Qin $=24$ kendaraan , Kendaraan keluar Qout $=7$ dan Kendaraan yang sudah ada $Q_{s}=25$ kendaraan maka akumulasi parkir sebagai berikut:

$=24-7+25$

$=42$ Kendaraan

Tabel 3. Rekapitulasi Akumulasi Parkir Hari Sabtu

Lokasi A Lokasi B

\begin{tabular}{llll}
\hline \multirow{2}{*}{ Interval } & \multicolumn{2}{c}{ Jumlah Kendaraan } & \multirow{2}{*}{ Akumulasi } \\
\cline { 2 - 3 } Mebuk & \multicolumn{2}{c}{ Keluar } & \\
\hline $06.00-06.30$ & 24 & 7 & 42 \\
\hline $06.30-07.00$ & 13 & 18 & 37 \\
\hline $07.00-07.30$ & 26 & 9 & 54 \\
\hline $07.30-08.00$ & 15 & 12 & 57 \\
\hline $\mathbf{0 8 . 0 0}-\mathbf{0 8}$. & & & \\
$\mathbf{3 0}$ & 18 & 14 & $\mathbf{6 1}$ \\
\hline $08.30-09.00$ & 19 & 22 & 58 \\
\hline $09.00-09.30$ & 11 & 19 & 50 \\
\hline $09.30-10.00$ & 6 & 9 & 47 \\
\hline $10.00-10.30$ & 6 & 9 & 44 \\
\hline $10.30-11.00$ & 3 & 5 & 42 \\
\hline $11.00-11.30$ & 2 & 14 & 30 \\
\hline $11.30-12.00$ & 0 & 5 & 25 \\
\hline Jumlah & 143 & 143 & \\
\hline $\begin{array}{l}\text { Jumlah } \\
\text { Kendraan } \\
\text { Yang Masih } \\
\text { Ada }\end{array}$ & & \\
\hline
\end{tabular}

\begin{tabular}{|c|c|c|c|}
\hline \multirow{2}{*}{ Interval } & \multicolumn{2}{|c|}{ Jumlah Kendaraan } & \multirow{2}{*}{ Akumulasi } \\
\hline & Masuk & Keluar & \\
\hline Sebelum & 10 & & \\
\hline $06.00-06.30$ & 5 & 1 & 14 \\
\hline $06.30-07.00$ & 16 & 2 & 28 \\
\hline $07.00-07.30$ & 29 & 9 & 48 \\
\hline $07.30-08.00$ & 1 & 15 & 34 \\
\hline $08.00-08.30$ & 4 & 6 & 32 \\
\hline $08.30-09.00$ & 2 & 3 & 31 \\
\hline $09.00-09.30$ & 7 & 4 & 34 \\
\hline $09.30-10.00$ & 2 & 2 & 34 \\
\hline $10.00-10.30$ & 3 & 2 & 35 \\
\hline $10.30-11.00$ & 2 & 7 & 31 \\
\hline $11.00-11.30$ & 3 & 6 & 28 \\
\hline $11.30-12.00$ & 0 & 7 & 21 \\
\hline Jumlah & 74 & 63 & \\
\hline $\begin{array}{l}\text { Jumlah } \\
\text { Kendraan } \\
\text { Yang Masih } \\
\text { Ada }\end{array}$ & & 21 & \\
\hline
\end{tabular}


Tabel 4. Rekapitulasi Akumulasi Parkir Hari Minggu

Lokasi A

\begin{tabular}{|l|l|l|l|}
\hline \multirow{2}{*}{ Interval } & \multicolumn{2}{c|}{ Jumlah Kendaraan } & \multirow{2}{*}{ Akumulasi } \\
\cline { 2 - 3 } & Masuk & \multicolumn{1}{|c|}{ Keluar } & \\
\hline Sebelum & 8 & & \\
\hline $06.00-06.30$ & 27 & 3 & 32 \\
\hline $06.30-07.00$ & 19 & 6 & 45 \\
\hline $07.00-07.30$ & 19 & 13 & 51 \\
\hline $07.30-08.00$ & 10 & 13 & 48 \\
\hline $\mathbf{0 8 . 0 0 - 0 8 . 3 0}$ & 14 & 9 & $\mathbf{5 3}$ \\
\hline $08.30-09.00$ & 4 & 10 & 47 \\
\hline $09.00-09.30$ & 5 & 8 & 44 \\
\hline $09.30-10.00$ & 5 & 6 & 43 \\
\hline $10.00-10.30$ & 8 & 9 & 42 \\
\hline $10.30-11.00$ & 4 & 6 & 40 \\
\hline $11.00-11.30$ & 2 & 14 & 28 \\
\hline $11.30-12.00$ & 0 & 6 & 22 \\
\hline $\begin{array}{l}\text { Jumlah } \\
\text { Jumlah }\end{array}$ & 117 & 103 & \\
$\begin{array}{l}\text { Kendraan } \\
\text { Yang Masih } \\
\text { Ada }\end{array}$ & & & \\
\hline
\end{tabular}

Lokasi B

\begin{tabular}{|l|l|l|l|}
\hline \multirow{2}{*}{ Interval } & \multicolumn{2}{c|}{ Jumlah Kendaraan } & \multirow{2}{*}{ Akumulasi } \\
\cline { 2 - 3 } & Masuk & Keluar & \\
\hline Sebelum & 17 & & \\
\hline $06.00-06.30$ & 19 & 1 & 35 \\
\hline $\mathbf{0 6 . 3 0}-\mathbf{0 7 . 0 0}$ & 10 & 2 & $\mathbf{4 3}$ \\
\hline $07.00-07.30$ & 7 & 10 & 40 \\
\hline $07.30-08.00$ & 5 & 10 & 35 \\
\hline $08.00-08.30$ & 2 & 3 & 34 \\
\hline $08.30-09.00$ & 2 & 5 & 31 \\
\hline $09.00-09.30$ & 2 & 1 & 32 \\
\hline $09.30-10.00$ & 1 & 5 & 28 \\
\hline $10.00-10.30$ & 7 & 3 & 32 \\
\hline $10.30-11.00$ & 2 & 3 & 31 \\
\hline $11.00-11.30$ & 2 & 6 & 27 \\
\hline $11.30-12.00$ & 2 & 5 & 24 \\
\hline Jumlah & 61 & 54 & \\
\hline $\begin{array}{l}\text { Jumlah } \\
\text { Kendraan } \\
\text { Yang Masih } \\
\text { Ada }\end{array}$ & & & \\
\hline
\end{tabular}

Berdasarkan Tabel 3 dan 4 diatas nilai akumulasi total kendaraan tertinggi pada penelitian hari sabtu lokasi parkir A yaitu sebanyak 61 kendaraan terjadi pada jam 08.00 - 08.30, dan akumulasi kendaraan terendah sebanyak 25 kendaraan pada jam 11.30 - 12.00. Sedangkan pada lokasi parkir B akumulasi tertinggi sebanyak 48 kendaraan terjadi pada jam 07.00 - 07.30, dan akumulasi terendah yaitu sebanyak 14 kendaraan terjadi pada jam 06.00 - 06.30. Sementara itu akumulasi kendaraan tertinggi pada penelitian hari minggu lokasi parkir A yaitu sebanyak 53 kendaraan terjadi pada jam $08.00-08.30$, dan akumulasi terendah sebanyak 22 kendaraan terjadi pada jam 11.30 - 12.00. Sedangkan akumulasi kendaraan tertinggi pada lokasi parkir B yaitu sebanyak 43 kendaraan terjadi pada jam $06.30-07.00$, dan akumulasi terendah yaitu sebanyak 24 kendaraan terjadi pada jam $11.30-12.00$.

\section{Durasi Parkir}

Perhitungan durasi parkir dibutuhkan untuk mengetahui lama kendaraan terparkir di area parkir. Contoh perhitungan durasi parkir pada hari sabtu lokasi parkir A (Departemen Perhubungan Direktur Jenderal Perhubungan Darat.1998). sebagai berikut :

$\mathrm{D}$

$$
\begin{aligned}
& =277: 168 \\
& =1,65 \sim 2 \text { Jam/Kendaraan }
\end{aligned}
$$

Tabel 5. Rekapitulasi Durasi Parkir Lokasi A dan B

\begin{tabular}{cccc}
\hline No & Lokasi Parkir & Tipe Kendaraan & $\begin{array}{c}\text { Durasi Rata-rata } \\
\text { Jam/Kendaraan }\end{array}$ \\
\hline 1 & A & Sepeda Motor & 1,65 \\
2 & B & Sepeda Motor & 2,16 \\
\hline \multirow{2}{*}{ No } & Lokasi Parkir & Tipe Kendaraan & Durasi Rata-rata \\
& & Jam/Kendaraan \\
\hline 1 & B & Sepeda Motor & 1,99 \\
2 & B & Sepeda Motor & 2,35 \\
\hline
\end{tabular}




\begin{tabular}{ccccc}
\hline & \multicolumn{3}{c}{ Jumlah Kendaraan Tiap Lokasi } \\
Parkir & \multicolumn{3}{c}{ Parki Parkir } & \multicolumn{2}{c}{ Sabtu } & \multicolumn{2}{c}{ Minggu } \\
& A & B & A & B \\
\hline $0-1$ & 114 & 38 & 83 & 34 \\
$1-2$ & 10 & 15 & 4 & 13 \\
$2-3$ & 3 & 4 & 0 & 5 \\
$3-4$ & 6 & 1 & 1 & 4 \\
$4-5$ & 16 & 16 & 6 & 1 \\
$5-6$ & 19 & 10 & 31 & 21 \\
\hline
\end{tabular}

\section{Tingkat Pergantian Parkir (Turnmover)}

Tingkat pergantian parkir (Turnmover) atau angka penggunaan ruang parkir dimaksudkan untuk melihat tingkat pemakaian ruang parkir selama waktu penelitian.(Departemen Perhubungan Direktur Jenderal Perhubungan Darat.1998).

Turnmover parkir kendaraan sepeda motor pada area parkir Pasar Pamarayan kabupaten serang bisa dilihat di Tabel 6 dan 7 Ruang parkir yang tersedia berdasarkan jumlah total petak parkir yang ada pada lokasi parkir A sebanyak 91 petak parkir dan lokasi parkir B sebanyak 36 petak parkir.

Tabel 6. Tingkat Pergantian Parkir Hari Sabtu Dan Minggu

\begin{tabular}{|c|c|c|c|c|}
\hline $\begin{array}{l}\text { Lokasi } \\
\text { Parkir }\end{array}$ & $\begin{array}{c}\text { Jumlah } \\
\text { Kendaraan }\end{array}$ & $\begin{array}{c}\text { Jumlah } \\
\text { SRP }\end{array}$ & Turnmover Kend/SRP/Jam & Pembulatan \\
\hline A & 168 & 91 & 1,85 & 2 \\
\hline B & 84 & 36 & 2,3 & 2 \\
\hline $\begin{array}{l}\text { Lokasi } \\
\text { Parkir }\end{array}$ & $\begin{array}{c}\text { Jumlah } \\
\text { Kendaraan }\end{array}$ & $\begin{array}{c}\text { Jumlah } \\
\text { SRP }\end{array}$ & Turnmover Kend/SRP/Jam & Pembulatan \\
\hline A & 125 & 91 & 1,37 & 1 \\
\hline $\mathrm{B}$ & 68 & 36 & 1,8 & 2 \\
\hline
\end{tabular}

Tingkat pergantian parkir yang diperoleh dari Tabel 6 hasil pengamatan diatas menunjukan bahwa Turnmover parkir terbesar yaitu 2,3 kendaraan/SRP/Jam terjadi di hari sabtu lokasi parkir B, dan tingkat pergantian parkir terkecil yaitu 1,37 kendaraan/SRP/Jam terjadi pada hari minggu lokasi parkir A.

\section{Kapasitas Ruang Parkir}

Kapasitas ruang parkir merupakan daya tampung sebuah lokasi parkir terhadap kendaraan.

Tabel 7. Kapasitas Parkir Hari Sabtu Dan Minggu

\begin{tabular}{ccccc}
\hline $\begin{array}{c}\text { Lokasi } \\
\text { Parkir }\end{array}$ & $\begin{array}{c}\text { Jumlah } \\
\text { SRP }\end{array}$ & $\begin{array}{c}\text { Durasi Rata- } \\
\text { rata }\end{array}$ & Total SRP/Jam/Kend & Pembulatan \\
\hline A & 91 & 1,65 & 55 & 55 \\
B & 36 & 2,16 & 16,6 & 17 \\
\hline Lokasi & Jumlah & $\begin{array}{c}\text { Durasi Rata- } \\
\text { rata }\end{array}$ & Total SRP/Jam/Kend & Pembulatan \\
Parkir & SRP & 1,99 & 45,7 & 46 \\
A & 91 & 2,35 & 15,3 & 15 \\
B & 36 & & &
\end{tabular}


Dari Tabel 6 dan 7 diatas dapat diketahui bahwa kapasitas parkir terbesar terdapat pada hari sabtu lokasi parkir A sebesar $55 \mathrm{SRP} / \mathrm{Jam} /$ Kendaraan, dan kapasitas terkecil terjadi pada hari minggu lokasi parkir B sebesar $15 \mathrm{SRP} / \mathrm{Jam} /$ Kendaraan.

\section{Indeks Parkir}

Indeks parkir merupakan perbandingan antara akumulasi parkir dengan kapasitas parkir yang tersedia.

Tabel 8. Indeks Parkir Hari Sabtu Dan Minggu

\begin{tabular}{cccc} 
Lokasi Parkir & Akumulasi & Kapasitas & IP x100\% \\
\hline A & 61 & 55 & $110 \%$ \\
B & 48 & 17 & $282 \%$ \\
Lokasi Parkir & Akumulasi & Kapasitas & IP x100\% \\
\hline A & 53 & 46 & $115 \%$ \\
B & 43 & 15 & $286 \%$ \\
\hline
\end{tabular}

Dari Tabel 8 diatas diketahui:

1) Lokasi parkir A dan B bermaslah, baik di hari sabtu maupun hari minggu. Ruang parkir yang ada tidak bisa menampung kebutuhan parkir, dikarenakan akumulasi tertinggi parkir melebihi kapasitas normal. Nilai IP $>100 \%$.

2) Lokasi parkir B sangat bermasalah, dikarenakan Indeks Parkir nya mencapai $282 \%$ dan $286 \%$ dari total 2 hari pengamatan.

\section{Kebutuhan Ruang Parkir}

Kebutuhan ruang parkir merupakan suatu ruang atau tempat yang dibutuhkan untuk menampung kendaraan yang akan parkir berdasarkan fasilitas dan fungsi dari tataguna lahan (Hobbs, F.D, 1997).

Tabel 9. Kebutuhan Ruang Parkir Hari sabtu Dan Minggu

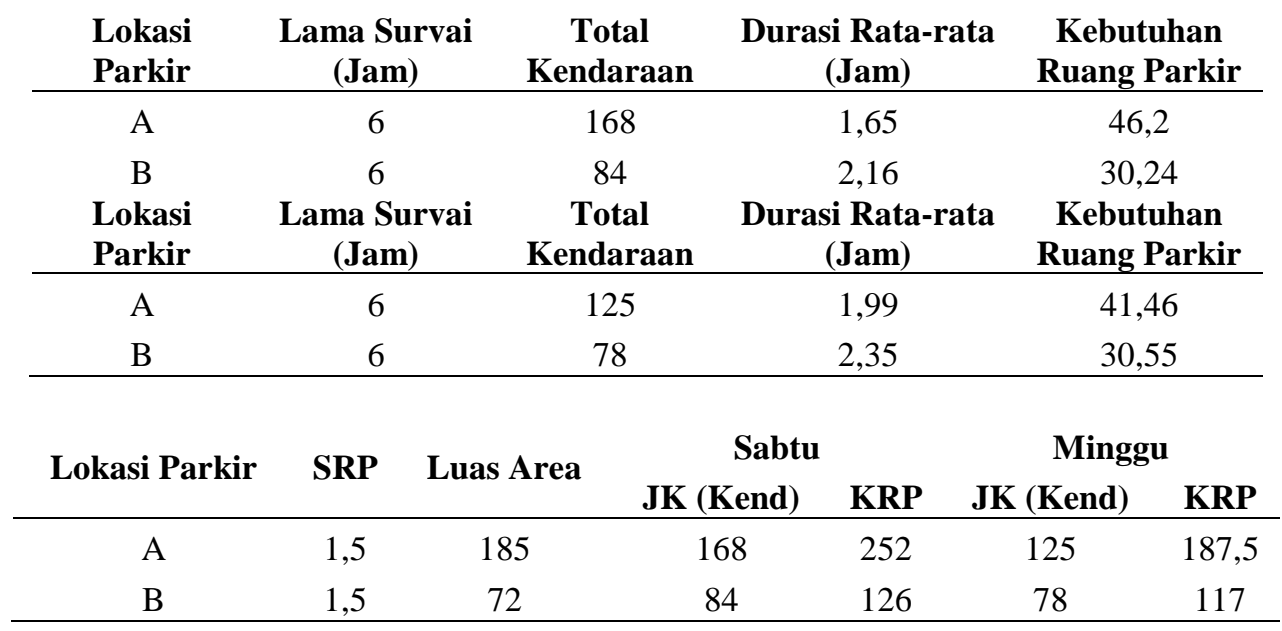

Dari Tabel 9. diatas dapat diketahui bahwa :

1) Lokasi parkir A pada hari sabtu membutuhkan ruang parkir seluas $252 \mathrm{M}^{2}$ dari total 168 kendaraan yang masuk area parkir, sedangkan luas area parkir yang tersedia hanya seluas 185 $\mathrm{M}^{2}$.

2) Lokasi parkir B pada hari sabtu membutuhkan ruang parkir seluas $126 \mathrm{M}^{2}$ dari total 84 kendaraan yang masuk area parkir, sedangkan luas area parkir yang tersedia hanya seluas 72 $\mathrm{M}^{2}$.

3) Lokasi parkir A pada hari mingggu membutuhkan ruang parkir seluas $187,5 \mathrm{M}^{2}$ dari total 125 kendaraan yang masuk area parkir, sedangkan luas area parkir yang tersedia hanya seluas 185 $\mathrm{M}^{2}$. 
4) Lokasi parkir B pada hari minggu membutuhkan ruang parkir seluas $117 \mathrm{M}^{2}$ dari total 168 kendaraan yang masuk area parkir, sedangkan luas area parkir yang tersedia hanya seluas 72 $\mathrm{M}^{2}$.

\section{KESIMPULAN DAN SARAN}

\section{KESIMPULAN}

Berdasarkan penelitian yang dilaksanakan dan data yang diperoleh maka penulis menyimpulkan sebagai berikut :

\section{Karakteristik Parkir}

Nilai akumulasi parkir tertinggi dari 2 (dua) hari penelitian dan 2 (dua) lokasi parkir yaitu terjadi pada penelitian hari sabtu di lokasi parkir A, sedangkan akumulasi terkecil terjadi pada hari minggu di lokasi parkir B. Durasi parkir rata-rata terbesar dari 2 (dua) hari penelitian dan 2 (dua) lokasi parkir yaitu terjadi pada hari minggu di lokasi parkir B, sedangkan durasi parkir rata-rata terkecil terjadi pada hari sabtu di lokasi parkir A. Tingkat (Turnmover) atau pergantian parkir terbesar terjadi pada hari sabtu di lokasi parkkir B, sedangkan tingkat (Turnmover) terkecil terjadi pada hari minggu di lokasi parkir A. Dari pengamatan yang dilakukan selama penelitian, 2 (dua) lokasi parkir yang ada ternyata bermaslah, Indeks Parkir menunjukan angka diatas $100 \%$.

3. Kebutuhan Ruang Parkir

Dari hasil pengamatan berikut analisis data yang telah dilakukan, luas area parkir Pasar Pamarayan yang ada saat ini tidak layak atau tidak dapat memenuhi kebutuhan ruang parkir kendaraan yang hendak parkir . Ruang parkir yang diperlukan melebihi luas area parkir yang terrsedia. Dimana kebutuhan masing-masing luas area parkir tiap lokasi sebagai berikut :

1) Lokasi parkir A pada hari sabtu membutuhkan ruang parkir seluas $252 \mathrm{M}^{2}$ dari total 168 kendaraan yang masuk area parkir, sedangkan luas area ruang parkir yang tersedia hanya sebesar $185 \mathrm{M}^{2}$.

2) Lokasi parkir B pada hari sabtu membutuhkan ruang parkir seluas $126 \mathrm{M}^{2}$ dari total 84 kendaraan yang masuk area parkir, sedangkan luas area ruang parkir yang tersedia hanya sebesar $72 \mathrm{M}^{2}$.

3) Lokasi parkir A pada hari mingggu membutuhkan ruang parkir seluas $187,5 \mathrm{M}^{2}$ dari total 125 kendaraan yang masuk area parkir, sedangkan luas area parkir yang tersedia hanya seluas $185 \mathrm{M}^{2}$.

4) Lokasi parkir $B$ pada hari minggu membutuhkan ruang parkir seluas $117 \mathrm{M}^{2}$ dari total 168 kendaraan yang masuk area parkir, sedangkan luas area parkir yang tersedia hanya seluas $72 \mathrm{M}^{2}$.

\section{SARAN}

Dengan kondisi yang ada saat ini maka penulis menawarkan beberapa solusi dari permasalahan Pasar Pamarayan sebagai berikut :

1) Pihak pengelola perlu melakukan penambahan area parkir dengan memanfaatkan lahan parkir yang ada dilengkapi dengan fasilitas parkir agar memudahkan pengunjung yang hendak parkir serta area parkir terlihat rapi dan tidak sembarang tempat.

2) Pihak pengelola perlu menerapkan kebijakan parkir agar tidak terjadi penumpukan kendaraan di lokasi parkir tertentu khusus nya di lokasi parkir A yang lokasinya persis didepan pasar dan pinggir jalan.

3) Dikarenakan perbedaan kebutuhan ruang parkir antara luas area yang ada dengan luas area parkir yang dibutuhkan tidak terpaut teralu jauh dan signifikan, untuk saaat ini dan solusi jangka pendeknya penulis menyarankan pada saat hari-hari pasar pada jam sibuk pengelola pasar melakukan rekayasa lalulintas berkoordinasi dengan pihak-pihak terkait dan dengan mengikuti prosedur yang ada untuk mengalihkan arus kendaraan yang akan melewati pasar kemudian diarahkan ke jalan alternatif terdekat agar ajan didepan pasar dapat digunakan sebagai lahan parkir sementara. Hal ini dapat dilakukan karna pasar pamarayan pada dasarnya beroperasi hanya sampai jam 12 siang. Akan tetapi siring bertambahnya angka kepemilikan kendaraan pada tahun tahun yang akan datang maka pihak pengelola pasar perlu mempertimbangkan untuk menyediakan lokasi parkir tambahan. 


\section{DAFTAR PUSTAKA}

Dayana, E.2012. Analisis Kebutuhan Parkir Kendaraan di Bandara Husein Sastranegara. Jurnal Teknik Sipil Fakultas Teknik dan Lingkungan. Institut Teknologi Bandung. Bandung.

Departemen Perhubungan Direktur Jenderal Perhubungan Darat.1998. Pedoman Teknis Penyelenggaraan Fasilitas Parkir.Jakarta : Departemen Perhubungan.

Hobbs, F.D, 1997, Perencanaan dan Teknik Lalu Lintas, Penerbit UGM, Jakarta.

Rosdiyani, T. 2016. Kajian Kebutuhan Ruang Parkir Sebagai Pengendali Lalu Lintas di Kampus Universitas muhamadiyah Surakarta,Tesis, Program Studi Teknik Sipil. Universitas Muhamadiyah Surakarta. Surakarta.

Royadji Darma dkk. 2019. Analisis Karakteristik Dan Kebutuhan Parkir di Pasar Tugu Bandar Lampung.Jurnal rekayasa Sipil Dan Desain. Universitas Lampung 